\title{
AS CONTRADIÇÕES DO \\ CICLO DE COMMODITIES
}

Júlio SÉrgio Gomes de Almeida

\section{RESUMO}

$\mathrm{O}$ artigo defende a necessidade de uma maior coordenação das políticas para conter os efeitos nocivos da supervalorização de commodities e possibilitar a retomada do crescimento econômico e do emprego doméstico. O Brasil arcará com um ônus elevado pela postura de abdicar de posições mais duradouras a médio e longo prazo em favor de benefícios que, por mais elevados que sejam, podem ser passageiros.

PALAVRAS-CHAVE: commodities; economia brasileira; crescimento econômico; macroeconomia.

\section{SUMMARY}

The article points out the necessity of better coordinated polices to avoid side effects of the overrating of commodities and stimulate economic growth and domestic employment. Brazil will pay a high price for its posture of leaving behind goals for the long run in favor of profits that might be ephemeral.

KEYWORDS: commodities; Brazilian economy; economic growth; macroeconomy.

[1] Para maiores informações, ver Baer, Monica e Cintra, Marcos Antonio Macedo. Brasil: investimento estrangeiro direto e estratégias empresariais. Santiago: Comissão Econômica para a América Latina e Caribe, setembro de 2004. (Uma versão simplificada desse trabalho está disponível em http://www.cepal.org).
A arquitetura da política macroeconômica brasileira parece enfrentar seus limites diante de mudanças no cenário interno e externo. Desde 1999, a política macroeconômica doméstica está sustentada em três pilares:as metas de inflação, a taxa de câmbio flutuante e os superávits fiscais. A taxa de juros alta e o câmbio valorizado têm sido cruciais para manter a inflação sob controle, e os superávits fiscais, para conter a expansão da dívida pública. Trata-se, portanto, de uma política econômica profundamente defensiva.

Após a desvalorização cambial ocorrida em 1999 e diante das frustrações renitentes com o fraco desempenho econômico brasileiro, as empresas passaram a adotar uma estratégia exportadora mais ativa, mediante um esforço comercial e de rearranjo da distribuição das linhas de produção entre as filiais das corporações multinacionais's. Em alguns casos, a escala do mercado interno e/ou a especialização, derivadas da dinâmica do mercado interno, também implicaram atividades exportadoras, inclusive bens tecnologicamente mais elaborados. Dessa forma, 
houve uma ampliação das vendas de produtos manufaturados de maiorvalor agregado, tais como autopeças, chassis, automóveis, tratores, aviões, bens de capital, eletroeletrônicos, bombas e centrífugas. A consolidação dos acordos comerciais com o Chile e com o México também impulsionou as vendas de caminhões, ônibus e máquinas agrícolas.

Em suma, o esforço exportador esteve associado à oportunidade de ocupação de capacidade produtiva ociosa, mas também a economias de escala, aumento da produtividade e algum adensamento tecnológico. Além dos ganhos de sinergia, acesso a novos mercados consumidores e aperfeiçoamento nos sistemas de distribuição, as exportações das empresas (estrangeiras e nacionais) têm proporcionado maior receita em moeda estrangeira, representando um mecanismo de hedge capaz de garantir as importações de peças e componentes, o pagamento das dívidas externas e redução do spread em novas captações no exterior, uma vez que contribui para melhorar a classificação de risco, abrindo linhas de crédito externas em condições mais favoráveis. As exportações se transformaram em operações estratégicas para as grandes empresas estrangeiras e nacionais e o Banco Nacional de Desenvolvimento Econômico e Social (BNDES) apoiou a expansão da produção destinada ao mercado internacional, sobretudo a indústria automobilística, aeronáutica e de máquinas e equipamentos. Dessa forma, acompanhou e facilitou a modificação das estratégias adotadas pelas corporações, seja pela participação direta no comércio exterior em produtos de maior conteúdo tecnológico e em áreas de maior expansão, seja pela associação ou compra de empresas locais, estimulando, por meio da concorrência, a reação das empresas brasileiras.

Esse movimento foi crucial para o enfrentamento da clássica restrição externa da economia brasileira: o saldo em transações correntes acrescido da expansão dos investimentos estrangeiros diretos, dado o dinamismo da economia e do comércio mundial, possibilitou o aumento das reservas internacionais e a eliminação do endividamento externo líquido do setor público. De acordo com Belluzzo:

no capitulo XXIII da Teoria Geral, Keynes trata, sob outra perspectiva, das "virtudes" do mercantilismo. Sustenta que um saldo positivo em conta corrente permitiria a queda da taxa de juro doméstica, ao injetar liquidez em moeda forte na economia nacional. Dada a relação câmbio/salário, a elevação do fluxo esperado de lucros pelos empresários vai estimular o investimento, a renda e o consumo. A dinâmica da economia estaria, portanto, apoiada no circuito exportações-acumulação de reservas-expansão do crédito-investimento-produtividade ${ }^{2}$.

[2] Belluzzo, Luiz Gonzaga de Mello. "Importações e crescimento anêmico". ValorEconômico, São Paulo, 6/o2/ 2007 . 
A menor vulnerabilidade externa da economia brasileira foi reconhecida por duas agências de classificação de risco de crédito - a Standard \& Poor's e a Fitch Ratings - , que concederam o grau de investimento ao país, entre abril e maio de 2008.

Enfim, esse arcabouço macroeconômico em um contexto de elevada liquidez internacional e de expansão da demanda mundial, sobretudo de commodities agrícolas, minerais e energéticas, impulsionou a taxa de crescimento das exportações (industriais e de produtos básicos) e do Produto Interno Bruto (PIB) brasileiro. Esse dinamismo trouxe novos problemas para a gestão macroeconômica. Dentro da lógica estrita da equação macroeconômica, parece evidente a necessidade de uma maior coordenação das políticas para conter os efeitos disruptivos de seu próprio êxito: a retomada do crescimento econômico e do emprego doméstico. No primeiro semestre de 2008 , o Comitê de Política Monetária (Copom) iniciou movimento de alta nas taxas de juros, para conter as pressões inflacionárias. A ampliação do diferencial entre os juros internos e externos, no entanto, facilita os processos de arbitragem e pressiona ainda mais a taxa de câmbio. Além disso, deteriora a gestão da dívida pública, realimentando as restrições aos investimentos em infra-estrutura, em um círculo vicioso.

A valorização cambial, por sua vez, tem efeitos contraditórios sobre a economia brasileira, sobretudo sobre o comércio exterior e a dinâmica industrial, cujas repercussões serão mais bem detalhadas abaixo. Por um lado, reduzem os preços de peças, componentes, máquinas e equipamentos importados, ampliando a inserção da estrutura industrial doméstica aos circuitos globalizados de produção e a modernização de vários segmentos, com o risco de desadensamento de algumas cadeias produtivas. Por outro lado, os preços elevados das commodities mantêm os saldos da balança comercial positivos, mesmo que decrescentes, dificultando um ajuste na taxa de câmbio. Para 2008 , projeta-se um superávit de US $\$ 52$ bilhões para o agronegócio e de US $\$ 25$ bilhões para a balança comercial.

Nesse contexto, as transações correntes voltaram a apresentar resultados negativos, recolocando o endividamento externo do país, a despeito de reservas internacionais acima de US $\$ 200$ bilhões. A taxa de juros básica não poderia ser elevada abruptamente, para não abortar os investimentos privados e valorizar ainda mais a taxa de câmbio, comprometendo as exportações de bens manufaturados. Como reordenar as prioridades dentro da equação macroeconômica atual, dada pela expansão da produção doméstica, pelo aumento das importações e pela queda nas exportações de manufaturados, sobretudo de bens de maior intensidade tecnológica?

De acordo com uma classificação da Organização para a Cooperação e o Desenvolvimento Econômico(OCDE), segundo a intensidade 
tecnológica do setor industrial, o saldo comercial gerado pela indústria de transformação (exportação menos importação) apresentou uma clara tendência ascendente entre os anos de 2002 e 2005 (ver Tabela 1)3. Em 2006, essa trajetória foi revertida. Em 2007, o bom desempenho das exportações de outros produtos (complexo soja, produtos animais, agricultura tropical — café, açúcar, frutas - indústria extrativa e serviços) que não fazem parte da indústria de transformação não conseguiu compensar a fraca performance desta última. $O$ superávit da balança comercial caiu.

$\mathrm{O}$ ano de 2007 representa um laboratório para a análise das tendências do comércio exterior brasileiro, uma vez que se combinou tanto um crescimento expressivo da demanda interna como uma valorização acentuada da taxa de câmbio. Como o país conta com uma estrutura industrial diversificada, o impulso da demanda doméstica levou a um crescimento expressivo da produção interna, mas aprofundou também um desequilíbrio comercial nos setores de alta e média-alta intensidade tecnológica. Assim, o ano de 2007 constitui uma amostra do que deve ocorrer na balança comercial da indústria se o "modelo" brasileiro de forte crescimento doméstico e valorização excessiva da moeda persistir.

O segmento de alta tecnologia, após obter as mais altas taxas de expansão no biênio 2005-2006, continuou se expandindo, mas em menor intensidade: $4,2 \%$, abaixo da indústria de transformação em sua totalidade (ver Tabela 1). O segmento apresentou déficit comercial durante todo o período, atingindo US $\$ 14,8$ bilhões em 2007 . Nesse setor persiste um problema estrutural de incapacidade da indústria doméstica de produzir bens de elevado conteúdo tecnológico, algo que somente uma arrojada política industrial poderia reverter. Todos os subsetores contribuíram para o déficit, com exceção da aeronáutica. Produtos farmacêuticos, de informática e escritório, além de instrumentos de precisão, perceberam déficits maiores do que em anos anteriores, puxados pela demanda doméstica. O maior déficit registrado nessa faixa, em 2007, foi em equipamentos de rádio, TV e comunicações, cuja produção caiu 1,1\%. Entre os produtos dessa atividade estão os componentes eletrônicos, muitos dos quais não são produzidos no Brasil, mas são bens intermediários em vários segmentos produtivos e que muito dificilmente virão a sê-lo a permanecer o nível apreciado da taxa de câmbio.

A produção industrial de média-alta intensidade tecnológica teve crescimento de dois dígitos, 12,7\%, alicerçada tanto em máquinas e equipamentos como na indústria automotiva e de equipamentos para ferrovia e outros de transporte, como motocicletas. Porém o setor químico, que cresceu 5,6\%, experimentou um déficit de US $\$ 3,9$ bilhões, eliminando o superávit da indústria automobilística. Ademais, a ampliação dos investimentos e a valorização cambial tanto impulsionaram a produção de máquinas e equipamentos mecânicos e elétricos,
[3] Para maiores informações, inclusive sobre a metodologia da OCDE, ver Almeida, Júlio Sérgio Gomes de e Almeida, Daniel Keller de. O comércio exterior em 2007. São Paulo: Instituto de Estudos para o Desenvolvimento Industrial, maio de 2008. Disponível em http://www.iedi.org.br. 
como as importações e, por conseguinte, os déficits desses produtos. Assim, o segmento de média-alta tecnologia, após registrar um resultado positivo em 2005 (superávit de US $\$ 443$ milhões) apresentou um déficit de US $\$ 10,3$ bilhões em 2007 . Justamente nesse segmento que a balança comercial mais se deteriorou (aumento das importações acima das exportações). Nesse caso, há também um problema industrial para ser enfrentado no âmbito da nova política industrial do governo, mas a valorização cambial é decisiva.

A produção fabril de média-baixa tecnologia aumentou em 5,1\% em 2007 , puxada pela indústria de produtos metálicos (com destaque para siderurgia), 6,4\%, também responsável pelo superávit desta faixa de intensidade. O saldo do conjunto dos produtos de média-baixa tecnologia caiu para US \$ 9,2 bilhões, mais do que o suficiente para contrabalançar os déficits de carvão e petróleo refinado e de produtos plásticos e de borracha.

Tabela I.

Saldo da Balança Comercial, Índice de Produção e Taxa de

Crescimento da Indústria de Transformação, por intensidade tecnológica.

\begin{tabular}{|c|c|c|c|c|c|c|}
\hline & 2002 & 2003 & 2004 & 2005 & 2006 & 2007 \\
\hline \multicolumn{7}{|c|}{ Balança comercial (US \$ milhões) } \\
\hline Demais Produtos & 6.233 & 8.175 & 9.791 & 13.871 & 16.616 & 21.250 \\
\hline Prod. Ind. Transformação & 6.969 & 16.723 & 24.053 & 31.107 & 29.796 & 18.779 \\
\hline Baixa & 15.363 & 19.856 & 25.197 & 28.727 & 31.927 & 34.761 \\
\hline Média-baixa & 3.068 & 5.488 & 8.871 & 10.258 & 10.545 & 9.185 \\
\hline Média-alta & -6.966 & -3.376 & -2.531 & 443 & -847 & -10.344 \\
\hline Alta & -4.496 & -5.245 & -7.484 & -8.320 & -11.779 & -14.824 \\
\hline Total & 13.202 & 24.899 & 33.843 & 44.978 & 46.412 & 40.028 \\
\hline \multicolumn{7}{|c|}{ Índice Prod. Ind. Transformação (base $2002=100$ ) } \\
\hline Total & 100,0 & 99,8 & 108,3 & 111,3 & 114,1 & 121,0 \\
\hline Baixa & 100,0 & 98.0 & 102,8 & 104,9 & 106,6 & 108,6 \\
\hline Média-baixa & 100,0 & 98,9 & 103,7 & 103,9 & 105,6 & 111,0 \\
\hline Média-alta & 100,0 & 103,6 & 120,0 & 123,2 & 126,0 & 141,9 \\
\hline Alta & 100,0 & 98,8 & 110,5 & 124,2 & 134,8 & 140,4 \\
\hline \multicolumn{7}{|c|}{ Ind. Transformação (taxa de crescimento) } \\
\hline Total & - & $-0,2$ & 8,5 & 2,7 & 2,6 & 6,0 \\
\hline Baixa & - & $-2,0$ & 4,9 & 2,0 & 1,7 & 1,8 \\
\hline Média-baixa & - & $-1,1$ & 4,8 & 0,2 & 1,7 & 5,1 \\
\hline Média-alta & - & 3,6 & 15,9 & 2,6 & 2,3 & 12,7 \\
\hline Alta & - & $-1,2$ & 11,8 & 12,4 & 8,5 & 4,2 \\
\hline
\end{tabular}


O setor industrial que menos cresceu foi o de baixo conteúdo tecnológico, com incremento de apenas 1,8\%. Foi, no entanto, o único a lograr ampliação do saldo comercial em 2007 , de US \$31,9 bilhões para US \$34,8 bilhões (ver Tabela 1). Obviamente isso decorre do histórico favorável desses produtos no mercado internacional, principalmente do setor de alimentos, associados ao agronegócio no qual o Brasil dispõe de vantagens competitivas notórias. Todas as atividades que compõem o segmento de baixa tecnologia foram superavitárias em 2007. O saldo comercial de bens típicos da indústria de alimentos, bebidase tabaco alcançou US\$24,6 bilhões, superando o superávit de todo o conjunto de bens inerentes à indústria de transformação, que não atingiu US \$19 bilhões. As indústrias de madeira, papel e celulose apresentaram o segundo maior superávit dentre os de baixa tecnologia, US \$ 6,4 bilhões, resultado que vem crescendo desde 1997. Já o superávit da indústria de têxteis, couro e calçados reduziu para US $\$ 3,3$ bilhões. Embora positivo, o saldo vem caindo paulatinamente desde 2004, com o segmento sentindo a competição dos importados.

Enfim, o fato de o crescimento recente ter sido alicerçado pela demanda interna e da porosidade existente em cadeias produtivas relevantes, nas quais ampliar a quantidade produzida de bens finais implica importar mais bens intermediários, conduziram a uma queda no superávit comercial dos produtos da indústria de transformação. Essa queda foi superlativa nos segmentos de alta e de média-alta intensidade tecnológica, cujo déficit conjunto atingiu US\$2 5,2 bilhões. Dessa forma, a economia brasileira permanece dependente, no que tange à geração de saldos comerciais, de produtos com baixa e média-baixa intensidade tecnológica, enquanto o setor de alta tecnologia é um grande importador e o maior gerador de déficits.

Esse padrão de comportamento se aprofundou no primeiro trimestre de 2008. De acordo com os dados disponíveis, a produção da indústria de transformação cresceu 6,3\% em relação ao mesmo período do ano passado. Esse aumento da produção foi acompanhado por deterioração vertiginosa do saldo comercial dos bens tipicamente produzidos pela indústria de transformação: o superávit de US \$ 5,5 bilhões no primeiro trimestre de 2007 cedeu lugar ao déficit de US\$ 179 milhões em igual período de 2008 . Aúltima vez em que a balança dos produtos da indústria de transformação experimentara déficit nos três meses iniciais do ano fora em 2001 . Ou seja, desde o primeiro trimestre de 2002, tais produtos vinham contribuindo para o superávit comercial brasileiro. Felizmente, a balança superavitária dos demais produtos, de US $\$ 3$ bilhões, manteve o saldo global da balança comercial brasileira com sinal positivo, de US $\$ 2,8$ bilhões.

Embora, as exportações de bens da indústria de transformação tenham crescido 13,6\% entre os dois períodos em questão(de US \$ 2 6,14 
bilhões para US $\$ 29,68$ bilhões), as importações se ampliaram em $44,6 \%$ (de US $\$ 20,65$ bilhões para US $\$ 29,86$ bilhões). É certo que a própria expansão da economia de um país amplia as importações. Mas o câmbio apreciado tem concorrido para tanto, principalmente em relação aos bens industriais sujeitos a economias de escala ou a estratégias de diferenciação visando ao consumidor.

Considerando os quatro segmentos por intensidade tecnológica (alta, média-alta, média-baixa e baixa), as faixas de alta e média-alta, que notoriamente congregam várias atividades sujeitas a estratégias de diferenciação de produtos, afora serem susceptíveis a economias de escala, apresentaram os maiores déficits. Os produtos de alta tecnologia experimentaram déficit comercial de US $\$ 4,6$ bilhões. O comportamento do saldo comercial desses bens persistiu em sentido contrário ao da produção física, que cresceu $3,7 \%$ entre os primeiros trimestres de $2007 \mathrm{e} 2008$. Esse fato se associa a outro: na linha marrom e de comunicações, está a fabricação de componentes eletrônicos, pouco expressiva na estrutura fabril do país, mas cujos produtos se constituem em bens intermediários relevantes para o complexo eletroeletrônico e têm sido cada vez mais representativos para outras indústrias à frente, como a aeronáutica, automobilística e a de máquinas e equipamentos. O segmento de áudio, vídeo e telecomunicações, mesmo com aumento de $10,2 \%$ na produção física em janeiro-março, registrou o maior déficit comercial dentre os ramos de alta tecnologia, US $\$ 1,8$ bilhão. As vendas externas de alta tecnologia foram puxadas pela indústria aeronáutica, a qual exportou US $\$ 1,3$ bilhão e conseguiu o único superávit dessa faixa tecnológica, de US $\$ 370$ milhões. Porém, a própria produção física e mesmo o acréscimo nas exportações dos bens de al to conteúdo tecnológico têm requerido importações de bens intermediários. O câmbio apreciado tende a ser forte obstáculo, seja para ampliar a cadeia produtiva eletrônica, seja para aumentare diversificar as exportações das atividades mais intensivas em tecnologia.

A faixa de média-alta intensidade tecnológica apresentou o maior déficit dentre os quatro segmentos, US $\$ 4,8$ bilhões. Nesse caso, 0 comportamento para primeiros trimestres vinha realçando uma mesma direção entre incremento da produção física e melhores resultados da balança comercial. Em janeiro-março de 2008 , isso mudou com a produção avançando pujantemente, $12,6 \%$, mas o saldo comercial se deteriorando sobejamente: o déficit se ampliou em praticamente US $\$ 2,5$ bilhões. Aliás, quase todos os segmentos de médiaalta tecnologia registraram déficit no período e de magnitude maior do que no trimestre inicial de 2007, mesmo com elevadas taxas de incremento na produção física. $O$ maior déficit foi experimentado pelos produtos químicos (exclusive farmacêuticos), de US $\$ 3,4$ bilhões, ainda que suas vendas para o exterior tenham alcançado seu maior 
patamar, de US \$ 2 bilhões, e sua produção tenha crescido 7\%. A exceção ficou por conta da indústria automobilística, superavitária em US\$ 829 milhões, porém com saldo inferior ao de janeiro-março de 2007 (US \$ 1,5 bilhão). Sua produção cresceu 19,4\%, superada dentro dessa faixa tecnológica apenas pela fabricação de material ferroviário e de outros meios de transporte, entre os quais se encontram as motocicletas, 21,5\%. Destaca-se ainda que a deterioração das balanças de máquinas e equipamentos, sejam elétricos, sejam mecânicos, abarca o dinamismo do investimento no país, principalmente ao se considerar a forte expansão de sua produção.

O superávit dos bens industriais de média-baixa tecnologia recuou para US\$903 milhões. Já os de baixa tecnologia foram os únicos a experimentar saldo melhor no primeiro trimestre de 2008 (US \$ 8,3 bilhões) vis-à-vis o acumulado equivalente de 2007 (US $\$ 7,6$ bilhões). Foi nessa faixa de baixa tecnologia que a produção menos cresceu no período, 1,8\%, patamar ditado em boa medida pelo segmento de alimentos, bebidas e fumo (1,4\%). Apesar da baixa variação, as exportações de alimentos, bebidas e fumo galgaram recordes, praticamente US $\$ 7$ bilhões, obtendo superávit de US $\$ 6$ bilhões. Os produtos do ramo madeireiro, seus derivados, papel e celulose também lograram superávit de US $\$ 1,7$ bilhão. Cumpre mencionar que esse conjunto de atividades, dentre as classificadas pela OCDE como de baixa tecnologia, foi aquele que mais ampliou sua produção física, em 3,9\%.A indústria de têxteis, couro e calçados, a seu turno, logrou incremento de $2,2 \%$, porém experimentou a terceira queda seguida em sua balança comercial na comparação entre acumulados até março, ficando com superávit de US\$ 601 milhões, o pior resultado de primeiro trimestre desde 2000.

Em suma, nos três meses de 2008 , as vendas externas do setor de bens manufaturados aumentaram com relação ao mesmo período de 2007, mas o quantum de produtos manufaturados não aumentou, pelo contrário, caiu. Assim, exclusivamente, os preços sustentaram e permitiram algum crescimento das exportações de manufaturas. $\mathrm{Na}$ média, os preços de exportação aumentaram 14,5\%. Duas questões são relevantes diante desse resultado. Em primeiro lugar, as commodities industriais tiveram a liderança do processo de aumento de preços, dada a elevada valorização que essa categoria de bens vem desfrutando no mercado mundial. Derivados do petróleo, manufaturados de ferro e aço, além de produtos cujo custo vem aumentando expressivamente, a exemplo de insumos agrícolas e produtos químicos, têm destaque nos maiores preços de manufaturados. Em segundo lugar, o esforço exportador de um país, assim como sua posição de dinamismo no comércio mundial,é medido pelo quantum e não por preços. Esses últimos estão, no presente momento, refletindo uma etapa de auge do 
Recebido para publicação em 28 de julho de 2008 .

\section{NOVOS ESTUDOS}

CEBRAP

81 , julho 2008

pp. 23-31 ciclo econômico mundial e, por isso, são passíveis de rápida reversão. O Brasil arcará com um ônus elevado por essa sua postura de abdicar de posições mais duradouras a médio e longo prazo em favor de benefícios que, por mais elevados que sejam, podem ser passageiros.

JÚlio SÉRGIO GOMES DE ALMEIDAé professor do Instituto de Economia da Universidade Estadual de Campinas (Unicamp) e consultor do Instituto de Estudos do Desenvolvimento Industrial (Iedi). 